\title{
DEFICIÊNCIA DE MACRONUTRIENTES E BORO EM MARACUJAZEIRO DOCE: QUALIDADE DOS FRUTOS ${ }^{1}$
}

\author{
MARTA SIMONE MENDONÇA FREITAS ${ }^{2}$, PEDRO HENRIQUE MONNERAT ${ }^{2}$, \\ LEANDRO GLAYDSON DA ROCHA PINHO ${ }^{2}$, ALMY JUNIOR CORDEIRO DE CARVALHO²
}

\begin{abstract}
RESUMO - Conduziu-se um experimento em casa de vegetação com o objetivo de avaliar a qualidade dos frutos de maracujazeiro doce cultivado sob deficiência de macronutrientes e B. O delineamento experimental foi em blocos casualizados, com o oito tratamentos (solução completa, -N, -P, -K, -Ca, -Mg, -S e -B), com quatro repetições. Utilizaram-se, como unidade experimental, caixas com $46 \mathrm{~kg}$ de areia lavada, contendo duas plantas/caixa, irrigadas com solução nutritiva. Todas as deficiências reduziram o número de frutos/planta, e sob deficiência de $\mathrm{Mg}$ as plantas não floresceram. As deficiências nutricionais não influenciaram no peso médio dos frutos, no $\mathrm{N}^{\mathrm{o}}$ de sementes/fruto, no comprimento do fruto e na porcentagem do suco. As deficiências de $\mathrm{N}$ e de $\mathrm{P}$ aumentaram a espessura e a concentração de casca do fruto. As deficiências de $\mathrm{N}$, de $\mathrm{P}$ e de $\mathrm{K}$ reduziram a concentração de sólidos solúveis totais; a de $\mathrm{K}$ reduziu a acidez total titulável; a de P reduziu o pH e aumentou a concentração da vitamina $\mathrm{C}$, enquanto a concentração de vitamina $\mathrm{C}$ foi reduzida pelas deficiências de $\mathrm{N}$, $\mathrm{K}$ e $\mathrm{S}$. As deficiências de $\mathrm{Ca}$ e de B não afetaram as características qualitativas avaliadas nos frutos.
\end{abstract}

Termos para indexação: Passiflora alata Curtis, nutrição de plantas, ${ }^{\circ}$ Brix, Vitamina C.

\section{MINERAL DEFICIENCY OF MACRONUTRIENTS AND BORON IN SWEET PASSION FRUIT: FRUIT QUALITY}

\begin{abstract}
An experiment was conducted in a greenhouse with the objective to evaluate the quality of the fruits of sweet passion fruit cultivated under deficiency of macronutrients and boron. Eight treatments with four replicates in a randomized complete block design were set up as follow: complete nutrient solution, $-\mathrm{N},-\mathrm{P},-\mathrm{K},-\mathrm{Ca},-\mathrm{Mg},-\mathrm{S}$ and $-\mathrm{B}$. The experimental unity was a plastic box filled with $46 \mathrm{~kg}$ of river sand containing two plants irrigated with the nutrient solutions. All deficiencies reduced the fruit number per plant, and under Mg deficiency no flowers were formed. None of the nutrition deficiencies influence the mean weight of the fruits, the number of seeds per fruit, the length of the fruit and the percentage of juice. The deficiencies of $\mathrm{N}$ and $\mathrm{P}$ increased peel thickness and concentration in the fruit and they reduced seed percentage in the fruit. The deficiencies of $\mathrm{N}, \mathrm{P}$ and $\mathrm{K}$ reduced the concentration of total soluble solids; $\mathrm{K}$ reduced the total titratable acidity; $\mathrm{P}$ reduced the $\mathrm{pH}$ and increased the vitamin $\mathrm{C}$ concentration, while the vitamin $\mathrm{C}$ concentration was reduced by the deficiencies of $\mathrm{N}, \mathrm{K}$ and $\mathrm{S}$. The characteristics of the fruits were not influenced by the deficiencies of $\mathrm{Ca}$ and $\mathrm{B}$.
\end{abstract}

Index Terms: Passiflora alata Curtis, mineral nutrition, ${ }^{\circ}$ Brix, vitamin C.

\section{INTRODUÇÃO}

Os frutos do maracujazeiro doce são consumidos principalmente ao natural, possuem aroma agradável, baixa acidez, elevados teores de sólidos solúveis totais, alto valor nutritivo, tamanho e aparência externa, o que os torna bem aceitos pelos consumidores. Alguns problemas, como a elevada espessura de casca e o baixo rendimento do suco, são citados como motivos para a depreciação do valor comercial dos frutos.

Dentre os fatores que influenciam na qualidade de frutos, a nutrição mineral é considerada um dos mais importantes. Carvalho et al. (2000), trabalhando com adubação nitrogenada e irrigação no maracujazeiro-amarelo, e avaliando a qualidade dos frutos, verificaram que a adubação nitrogenada aumentou o número de frutos por ha, porém não influenciou no peso médio nem em outras características qualitativas dos frutos. Fontes (2005), trabalhando com doses de $\mathrm{N}$ aplicadas via fertirrigação em maracujazeiro-amarelo, verificou que o aumento na dose do adubo nitrogenado provocou redução nos teores de sólidos solúveis totais. Carvalho et al. (1999) verificaram que, em maracujazeiro-amarelo, quanto maior as doses de $\mathrm{K}$, maiores são as concentrações de suco e de ${ }^{\circ}$ Brix.

Hunsche et al. (2003), trabalhando com doses de K em maçãs Fuji, verificaram que a deficiência de K no solo resulta em frutos pequenos, mais firmes, com menor teor de ácidos e menor coloração vermelha na colheita em comparação aos frutos oriundos de plantas bem supridas de K. Bologna (2003) observou que o aumento da dose de B diminui a porcentagem de suco em frutos de laranja-pêra.
Com relação à qualidade dos frutos do maracujazeiro doce, não foram encontrados, na literatura, resultados científicos estudando os efeitos da deficiência nutricional na qualidade dos frutos. Nesse sentido, o objetivo deste trabalho foi verificar o efeito das deficiências de $\mathrm{N}, \mathrm{P}, \mathrm{K}, \mathrm{Ca}, \mathrm{Mg}, \mathrm{S}$ e B sobre a qualidade dos frutos do maracujazeiro doce.

\section{MATERIAL E MÉTODOS}

O experimento foi realizado em casa de vegetação, na Universidade Estadual do Norte Fluminense Darcy Ribeiro, localizada em Campos dos Goytacazes - RJ (Latitude $=21^{\circ} 19^{\prime} 23^{\prime \prime}$; Longitude $=41^{\circ} 10^{\prime} 40^{\prime \prime} \mathrm{W}$; Altitude $=14 \mathrm{~m}$ ), de 30-09-2004 a 12-11-2005. Durante a condução do experimento, no período de desenvolvimento e colheita dos frutos, de maio a outubro de 2005 , dentro da casa de vegetação, as temperaturas diárias máximas variaram, entre os meses, de 32,5 a $38,0^{\circ} \mathrm{C}$, com média das máximas igual a $34,5^{\circ} \mathrm{C}$, as temperaturas diárias mínimas entre 17,5 e $21,5^{\circ} \mathrm{C}$, com média das mínimas igual a $18,9^{\circ} \mathrm{C}$ e a temperatura média diária variando de 24,5 a $32,5^{\circ} \mathrm{C}$, com média igual a $27,9^{\circ} \mathrm{C}$.

O delineamento experimental foi de blocos casualizados, com oito tratamentos: completo (testemunha), deficiente em nitrogênio $(-\mathrm{N})$, deficiente em fósforo (-P), deficiente em potássio (-K), deficiente em cálcio (-Ca), deficiente em magnésio (-Mg), deficiente em enxofre $(-S)$ e deficiente em boro (-B), com quatro repetições. A unidade experimental foi composta por uma caixa com 46 litros de areia lavada e duas plantas por caixa.

\footnotetext{
${ }^{1}$ (Trabalho 28-2006). Recebido: 13-03-2006. Aceito para publicação: 25-08-2006. Parte da Tese de Doutorado em Produção Vegetal do Primeiro Autor na UENF. Projeto financiado pelo CNPq.

${ }^{3}$ UENF/CCTA, Campos dos Goytacazes - RJ, 28013-603.msimone@uenf.br, monnerat@uenf.br, pinho@uenf.br, almy@uenf.br
} 
Durante o crescimento das plantas, quando elas apresentavam sintomas de deficiência muito severos, que conduziriam à sua morte ou que impediam seu florescimento, foi necessário reaplicar soluções contendo o nutriente sob deficiência. Neste sentido, aplicou-se, nos tratamento $-\mathrm{N}$, $-\mathrm{K}$ e -Mg, solução completa por um período de 5 dias. Nos tratamentos $-\mathrm{Ca}$ e $-\mathrm{B}$, a solução completa foi colocada por um período de 30 dias. Para os tratamentos -P e -S, aplicou-se, por 5 dias, solução contendo 10 e $20 \%$ de cada nutriente específico.

Utilizaram-se, como material propagativo, sementes retiradas de frutos de maracujazeiro doce, adquiridos no comércio de Campos dos Goytacazes-RJ, cuja origem foi de plantios comerciais em Campinas-SP. As sementes foram tratadas para a quebra de dormência, utilizando-se de escarificação com areia e imersão por 24 horas em ácido giberélico na concentração de $300 \mathrm{mg} \mathrm{L}^{-1}$. A semeadura foi realizada no dia 30-09-2004 em bandejas de isopor de 72 células, com capacidade para $100 \mathrm{~mL}$ de substrato/célula, que continham areia lavada. $\mathrm{O}$ transplantio de 6 mudas para as caixas de plástico, que continham $46 \mathrm{~L}$ de areia lavada, foi realizado 45 dias após a semeadura. As mudas foram irrigadas diariamente, por 10 dias, com solução nutritiva completa a 50\% e depois a $100 \%$ (Tabela 1). Com 15 dias que as plantas estavam nas caixas, foi realizado um desbaste, deixando 3 plantas/caixa. Com 64 dias de transplantio, eliminou-se uma planta por caixa, deixando ao final, as duas mais uniformes.

As plantas foram conduzidas em haste única até atingirem o arame superior da espaldeira, a 1,8 $\mathrm{m}$ de altura, quando foram despontadas, realizando-se a condução de dois ramos laterais. Os ramos laterais foram despontados quando atingiam $1,25 \mathrm{~m}$, para induzir o crescimento dos ramos terciários e, assim, formar uma cortina. O espaçamento utilizado foi de $2 \mathrm{~m}$ entre linhas e 2,5 m entre caixas na linha.

Com 66 dias do transplantio, a solução completa foi reduzida para 50\% em todas as parcelas, e sete dias após iniciou-se a aplicação dos tratamentos, omitindo-se, totalmente, os nutrientes $\mathrm{N}, \mathrm{P}, \mathrm{K}, \mathrm{Ca}$, $\mathrm{Mg}, \mathrm{S}$ e B nas parcelas respectivas. As soluções utilizadas no experimento encontram-se na Tabela 1 , sendo que o $\mathrm{pH}$ delas foi sempre ajustado para 5,4. As soluções nutritivas foram baseadas em Johnson et al. (1957), com modificações. Foram aplicados diariamente, com o auxílio de um regador manual, $5 \mathrm{~L}$ de solução por caixa.
A colheita dos frutos iniciou-se aos 177 dias após o início da aplicação dos tratamentos, estendendo-se até 280 dias, sendo analisados todos os frutos de cada parcela.

Para a determinação das características qualitativas do fruto e do suco, os frutos foram colhidos no estádio pré-climatério, dado pela mudança da coloração verde-clara para amarela na parte apical do fruto. Nestes frutos, determinaram-se o peso médio, o comprimento, o diâmetro, a espessura da casca, a porcentagem de casca e de suco, o pH, determinado através de leitura direta de amostras do suco em potenciômetro digital, os sólidos solúveis totais - SST ( ${ }^{\circ}$ Brix), determinado com refratômetro manual, a acidez total titulável (ATT), determinada a partir de $5 \mathrm{~mL}$ de suco, usandose indicador fenolftaleína, seguido por titulação com $\mathrm{NaOH} 0,1 \mathrm{~N}$ e expressa em g de ácido cítrico por $100 \mathrm{~mL}$ de suco $\{$ ATT $=($ Vol de $\mathrm{NaOH} \times$ normalidade $(0,1 \mathrm{~N}) \times 0,064 \times 100) /$ peso da amostra em $\mathrm{g}$ \} e a vitamina $\mathrm{C}$, obtida pela titulação com 2,6 diclorofenol-indofenol e expressa em mg de ácido ascórbico por $100 \mathrm{~mL}$ de suco.

Determinaram-se, ainda, aos 240 dias após o início da aplicação dos tratamentos, os teores de macronutrientes e de B na matéria seca da $4^{\mathrm{a}}$ folha totalmente expandida do maracujazeiro doce, utilizando-se de metodologia descrita por Malavolta et al. (1997).

Foi realizada análise de variância, e as médias foram comparadas com a testemunha (tratamento completo) pelo teste bilateral de Dunnet, a 5\% de probabilidade, utilizando-se do Sistema de Análise Estatística (SANEST), desenvolvido pelo CIAGRI/USP.

\section{RESULTADOS E DISCUSSÃO}

As plantas cultivadas sob deficiência de N, P, K, Ca, S e B produziram menor número de frutos do que o tratamento completo $\mathrm{e}$ não houve produção de frutos nas plantas sob deficiência de $\mathrm{Mg}$ (Tabela 2). Segundo Malavolta et al. (1997), as deficiências de Pe Ca reduzem o número de frutos/planta, e a deficiência de $\mathrm{P}$ reduz o número de sementes/fruto. Araújo et al. (2005), estudando os efeitos da nutrição potássica sobre o crescimento e a produção do maracujazeiro-amarelo, verificaram que o incremento da concentração de potássio na solução nutritiva provocou aumento linear no número de frutos/planta.

O peso médio, o comprimento, o diâmetro e o número de sementes de frutos do maracujazeiro doce obtido neste trabalho (Tabela 2) estão dentro de faixas encontradas por Meletti et al. (2003),

TABELA 1 - Composição das soluções nutritivas, completa e deficiente em N, P, K, Ca, Mg, S e B, utilizadas no experimento do maracujazeiro doce. Campos dos Goytacazes - RJ. 2005

\begin{tabular}{|c|c|c|c|c|c|c|c|c|}
\hline \multirow{3}{*}{ Solução-estoque } & \multicolumn{8}{|c|}{ Tratamentos } \\
\hline & Completo & $-\mathbf{N}$ & $-\mathbf{P}$ & $-\mathbf{K}$ & $-\mathbf{C a}$ & $-\mathrm{Mg}$ & $-\mathbf{S}$ & $-\mathbf{B}$ \\
\hline & & & & $\mathrm{mL} \mathrm{L}$ & - & & & -- \\
\hline $\mathrm{Ca}\left(\mathrm{NO}_{3}\right)_{2}{ }_{4} \mathrm{H}_{2} \mathrm{O}\left(2 \mathrm{~mol} \mathrm{~L}^{-1}\right)$ & 1,5 & - & 1,5 & 1,5 & - & 1,5 & 1,5 & 1,5 \\
\hline $\mathrm{KNO}_{3} \quad\left(2 \mathrm{~mol} \mathrm{~L}^{-1}\right)$ & 2,0 & - & 2,0 & - & 2,0 & 2,0 & 2,0 & 2,0 \\
\hline $\mathrm{NH}_{4} \mathrm{H}_{2} \mathrm{PO}_{4}\left(1 \mathrm{~mol} \mathrm{~L}^{-1}\right)$ & 0,5 & - & - & 0,5 & 0,5 & 0,5 & 0,5 & 0,5 \\
\hline $\mathrm{MgSO}_{4}\left(1 \mathrm{~mol} \mathrm{~L}^{-1}\right)$ & 2,0 & 2,0 & 2,0 & 2,0 & 2,0 & - & - & 2,0 \\
\hline FeEDTA $\left(25 \mathrm{~g} \mathrm{~L}^{-1}\right)$ & 1,0 & 1,0 & 1,0 & 1,0 & 1,0 & 1,0 & 1,0 & 1,0 \\
\hline MICRO* & 1,0 & 1,0 & 1,0 & 1,0 & 1,0 & 1,0 & 1,0 & 1,0 \\
\hline $\mathrm{H}_{3} \mathrm{BO}_{3}(25 \mathrm{mM})$ & 1,0 & 1,0 & 1,0 & 1,0 & 1,0 & 1,0 & 1,0 & - \\
\hline$\left(\mathrm{NH}_{4}\right)_{2} \mathrm{SO}_{4}\left(1 \mathrm{~mol} \mathrm{~L}^{-1}\right)$ & 0,5 & - & 0,5 & 0,5 & 0,5 & 0,5 & - & 0,5 \\
\hline $\mathrm{NH}_{4} \mathrm{Cl}\left(1 \mathrm{~mol} \mathrm{~L}^{-1}\right)$ & - & - & 0,5 & - & - & - & 1,0 & - \\
\hline $\mathrm{NaNO}_{3}\left(2 \mathrm{~mol} \mathrm{~L}^{-1}\right)$ & - & - & - & 2,0 & 3,0 & - & - & - \\
\hline $\mathrm{Na}_{2} \mathrm{SO}_{4}\left(1 \mathrm{~mol} \mathrm{~L}^{-1}\right)$ & - & - & - & - & - & 2,0 & - & - \\
\hline $\mathrm{MgCl}_{2}\left(1 \mathrm{~mol} \mathrm{~L}^{-1}\right)$ & - & - & - & - & - & - & 2,0 & - \\
\hline $\mathrm{CaCl}_{2} \quad\left(2 \mathrm{~mol} \mathrm{~L}^{-1}\right)$ & - & 1,5 & - & - & - & - & - & - \\
\hline $\mathrm{KCl} \quad\left(1 \mathrm{~mol} \mathrm{~L}^{-1}\right)$ & - & 2,5 & - & - & - & - & - & - \\
\hline $\mathrm{KH}_{2} \mathrm{PO}_{4}\left(1 \mathrm{~mol} \mathrm{~L}^{-1}\right)$ & - & 0,5 & - & - & - & - & - & - \\
\hline $\mathrm{K}_{2} \mathrm{SO}_{4} \quad\left(0,5 \mathrm{~mol} \mathrm{~L}^{-1}\right)$ & - & 1,0 & - & - & - & - & - & - \\
\hline
\end{tabular}


TABELA 2 - Parâmetros de qualidade de fruto do maracujazeiro doce cultivado sob deficiência de macronutrientes e B. Campos dos Goytacazes - RJ. 2005

\begin{tabular}{|c|c|c|c|c|c|c|}
\hline Tratamento & $\begin{array}{c}\text { Número } \\
\text { de frutos } \\
\text { por planta }\end{array}$ & $\begin{array}{l}\text { Peso de } \\
\text { fruto } \\
\text { (g) }\end{array}$ & $\begin{array}{c}\text { Diâmetro } \\
\text { de fruto } \\
\text { (cm) }\end{array}$ & $\begin{array}{c}\text { Comprimento } \\
\text { de fruto } \\
(\mathrm{cm})\end{array}$ & $\begin{array}{c}\mathrm{N}^{\mathbf{o}} \text { de } \\
\text { sementes } \\
\text { por fruto } \\
\end{array}$ & $\begin{array}{c}\text { Espessura } \\
\text { da casca } \\
(\mathrm{mm}) \\
\end{array}$ \\
\hline Completo & 10 & 199 & 6,91 & 9,7 & 264 & 9,30 \\
\hline$-\mathbf{N}$ & $2^{-}$ & $255^{\mathrm{ns}}$ & $7,75^{+}$ & $10,8^{\mathrm{ns}}$ & $183^{\mathrm{ns}}$ & $11,63^{+}$ \\
\hline$-\mathbf{P}$ & $3^{-}$ & $233^{\mathrm{ns}}$ & $7,64^{\mathrm{ns}}$ & $12,7^{\mathrm{ns}}$ & $187^{\mathrm{ns}}$ & $11,29^{+}$ \\
\hline$-K$ & $6^{-}$ & $158^{\mathrm{ns}}$ & $6,65^{\mathrm{ns}}$ & $8,6^{\mathrm{ns}}$ & $262^{\mathrm{ns}}$ & $8,53^{\mathrm{ns}}$ \\
\hline$-\mathrm{Ca}$ & $6^{-}$ & $210^{\mathrm{ns}}$ & $7,15^{\mathrm{ns}}$ & $9,7^{\mathrm{ns}}$ & $258^{\mathrm{ns}}$ & $9,46^{\mathrm{ns}}$ \\
\hline$-\mathbf{M g}$ & $0^{-}$ & - & - & - & - & - \\
\hline$-S$ & $4^{-}$ & $204^{\mathrm{ns}}$ & $7,00^{\text {ns }}$ & $10,3^{\mathrm{ns}}$ & $205^{\mathrm{ns}}$ & $9,73^{\mathrm{ns}}$ \\
\hline$-B$ & $7^{-}$ & $177^{\mathrm{ns}}$ & $6,85^{\mathrm{ns}}$ & $8,7^{\mathrm{ns}}$ & $234^{\mathrm{ns}}$ & $9,45^{\mathrm{ns}}$ \\
\hline CV (\%) & 29,3 & 15,2 & 5,2 & 17,9 & 18,5 & 8,94 \\
\hline
\end{tabular}

+ Significativo e superior à testemunha (Completo), pelo teste de Dunnet, em nível de 5\% de probabilidade;

- Significativo e inferior à testemunha (Completo), pelo teste de Dunnet, em nível de 5\% de probabilidade;

ns Não-significativo, pelo teste de Dunnet, em nível de 5\% de probabilidade.

TABELA 3 - Parâmetros de qualidade do fruto do maracujazeiro doce cultivado sob deficiência de macronutrientes e B. Campos dos Goytacazes - RJ. 2005

\begin{tabular}{|c|c|c|c|c|c|c|c|}
\hline Tratamento & $\begin{array}{c}\text { Casca } \\
(\%)\end{array}$ & $\begin{array}{c}\text { Suco } \\
(\%)\end{array}$ & $\begin{array}{c}\text { Semente } \\
(\%)\end{array}$ & $\begin{array}{c}\text { SST } \\
\left({ }^{\circ} \text { Brix) }\right.\end{array}$ & $\begin{array}{c}\text { ATT } \\
\text { (g de ácido } \\
\text { cítrico/100 } \\
\text { mL de suco) }\end{array}$ & pH & $\begin{array}{c}\text { Vitamina C } \\
(\mathrm{mg} / 100 \mathrm{~g} \\
\text { de suco) }\end{array}$ \\
\hline Completo & 69 & 22 & 9 & 20,8 & 1,70 & 3,53 & 12,86 \\
\hline$-\mathbf{N}$ & $76^{+}$ & $18^{\mathrm{ns}}$ & $5^{-}$ & $18,6^{-}$ & $1,56^{\mathrm{ns}}$ & $3,52^{\mathrm{ns}}$ & $9,06^{-}$ \\
\hline$-\mathbf{P}$ & $76^{+}$ & $18^{\mathrm{ns}}$ & $6^{-}$ & $18,9^{-}$ & $1,58^{\mathrm{ns}}$ & $3,42^{-}$ & $19,65^{+}$ \\
\hline$-\mathbf{K}$ & $65^{\mathrm{ns}}$ & $25^{\mathrm{ns}}$ & $10^{\mathrm{ns}}$ & $17,8^{-}$ & $1,36^{-}$ & $3,46^{\mathrm{ns}}$ & $10,39^{-}$ \\
\hline$-\mathbf{C a}$ & $68^{\mathrm{ns}}$ & $24^{\mathrm{ns}}$ & $8^{\mathrm{ns}}$ & $19,4^{\mathrm{ns}}$ & $1,79^{\mathrm{ns}}$ & $3,53^{\mathrm{ns}}$ & $12,65^{\mathrm{ns}}$ \\
\hline$-S$ & $67^{\mathrm{ns}}$ & $25^{\mathrm{ns}}$ & $8^{\text {ns }}$ & $21,0^{\mathrm{ns}}$ & $1,64^{\mathrm{ns}}$ & $3,56^{\mathrm{ns}}$ & $10,31^{-}$ \\
\hline$-B$ & $69^{\text {ns }}$ & $23^{\text {ns }}$ & $9^{\text {ns }}$ & $20,0^{\mathrm{ns}}$ & $1,73^{\mathrm{ns}}$ & $3,52^{\text {ns }}$ & $12,16^{\mathrm{ns}}$ \\
\hline CV (\%) & 2,68 & 9,54 & 16,9 & 4,05 & 8,09 & 1,33 & 4,43 \\
\hline
\end{tabular}

+Significativo e superior à testemunha (Completo), pelo teste de Dunnet, em nível de $5 \%$ de probabilidade; -Significativo e inferior à testemunha (Completo), pelo teste de Dunnet, em nível de 5\% de probabilidade; ns - Não-significativo, pelo teste de Dunnet, em nível de 5\% de probabilidade.

TABELA 4 - Teores de macronutrientes e B em folhas de maracujazeiro doce, aos 240 dias após o início do tratamento com omissão dos nutrientes. Campos dos Goytacazes - RJ. 2005

\begin{tabular}{|c|c|c|c|c|c|c|c|}
\hline & $\mathbf{N}$ & $\mathbf{P}$ & $\mathbf{K}$ & $\mathbf{C a}$ & $\mathrm{Mg}$ & $\mathbf{S}$ & B \\
\hline Tratamento & --------. & --------- & -------- & $\mathrm{kg}^{-1}-$ & -1 & ------ & $\mathrm{mg} \mathrm{kg}^{-1}$ \\
\hline Completo & 41,5 & 3,05 & 27,6 & 7,70 & 3,92 & 4,93 & 49,0 \\
\hline$-\mathbf{N}$ & $26,6^{-}$ & $3,19^{\mathrm{ns}}$ & $36,5^{+}$ & $8,10^{\mathrm{ns}}$ & $3,69^{\mathrm{ns}}$ & $4,44^{\mathrm{ns}}$ & $65,1^{\mathrm{ns}}$ \\
\hline$-\mathbf{P}$ & $42,4^{\mathrm{ns}}$ & $1,91^{-}$ & $26,6^{\mathrm{ns}}$ & $6,94^{\mathrm{ns}}$ & $3,45^{\mathrm{ns}}$ & $5,22^{\mathrm{ns}}$ & $55,2^{\mathrm{ns}}$ \\
\hline$-K$ & $43,1^{\mathrm{ns}}$ & $3,02^{\mathrm{ns}}$ & $12,5^{-}$ & $10,0^{+}$ & $5,32^{+}$ & $4,13^{\mathrm{ns}}$ & $58,8^{\mathrm{ns}}$ \\
\hline$-\mathrm{Ca}$ & $44,8^{\mathrm{ns}}$ & $4,09^{\mathrm{ns}}$ & $27,6^{\mathrm{ns}}$ & $2,84^{-}$ & $5,49^{+}$ & $5,00^{\mathrm{ns}}$ & $53,3^{\mathrm{ns}}$ \\
\hline$-M g$ & $48,9^{\text {ns }}$ & $3,69^{\mathrm{ns}}$ & $35,7^{+}$ & $6,65^{\mathrm{ns}}$ & $1,34^{-}$ & $5,45^{\mathrm{ns}}$ & $44,3^{\mathrm{ns}}$ \\
\hline$-S$ & $43,8^{\mathrm{ns}}$ & $3,39^{\mathrm{ns}}$ & $34,1^{+}$ & $7,18^{\mathrm{ns}}$ & $4,48^{\mathrm{ns}}$ & $0,67^{-}$ & $51,0^{\mathrm{ns}}$ \\
\hline$-B$ & $43,3^{\text {ns }}$ & $3,20^{\mathrm{ns}}$ & $27,9^{\text {ns }}$ & $6,08^{\mathrm{ns}}$ & $3,95^{\mathrm{ns}}$ & $4,87^{\mathrm{ns}}$ & $15,7^{-}$ \\
\hline CV (\%) & 8,92 & 16,8 & 10,4 & 15,3 & 15,6 & 14 & 19,2 \\
\hline
\end{tabular}

+ Significativo e superior à testemunha (Completo), pelo teste de Dunnet, em nível de 5\% de probabilidade;

- Significativo e inferior à testemunha (Completo), pelo teste de Dunnet, em nível de 5\% de probabilidade;

ns Não-significativo, pelo teste de Dunnet, em nível de 5\% de probabilidade.

em condições de campo, no Estado de São Paulo. Silva et al. (2004), trabalhando com maracujazeiro doce em condições de campo, no município de Selvíria-MS, obtiveram peso de frutos de 189 a $198 \mathrm{~g}$, com comprimento médio igual a 10,6 cm e diâmetro médio igual a 7,1 $\mathrm{cm}$. Vasconcellos et al. (1993), cultivando maracujazeiro doce em condições de campo, em Botucatu-SP, obtiveram peso médio de frutos igual a $253,13 \mathrm{~g}$, com comprimento de $9,59 \mathrm{~cm}$, diâmetro de $8,16 \mathrm{~cm}$ e número de sementes/fruto igual a 303. Detoni et al. (2001), trabalhando com maracujazeiro doce em condições de campo, no município de Pato Bragato-PR, obtiveram peso de frutos com média de $141 \mathrm{~g}$, com comprimento médio igual a $9,86 \mathrm{~cm}$ e diâmetro médio igual a $9,50 \mathrm{~cm}$.

Os resultados encontrados para o peso médio dos frutos do maracujá doce, no tratamento conduzido sob deficiência de nitrogênio, estão de acordo com aqueles encontrados em maracujáamarelo por Carvalho et al. (2000) e em mamão por Marinho et al. (2001). Carvalho et al. (1999) observaram que a adubação potássica promoveu o aumento no peso médio de frutos do maracujazeiro- 
amarelo.

Para o diâmetro do fruto do maracujazeiro doce, observa-se, na Tabela 2, que houve um incremento de $12 \%$, quando as plantas foram cultivadas sob deficiência de N. Para os outros tratamentos, não foi verificada diferença significativa em relação ao tratamento completo. Carvalho et al. (2000) e Carvalho et al. (1999), trabalhando com maracujazeiro-amarelo, não verificaram influência de adubação potássica e nitrogenada no diâmetro de frutos.

Não foi observado efeito dos tratamentos que produziram frutos na concentração de suco do maracujazeiro doce, sendo que, no tratamento completo, a média obtida foi de $22 \%$ (Tabela 3). Plantas cultivadas sob deficiência de $\mathrm{N}$ e de $\mathrm{P}$ produziram frutos com maior espessura da casca (Tabela 2) e maior porcentagem de casca e menor porcentagem de sementes em relação ao tratamento completo (Tabela 3). Vasconcellos et al. (1993) obtiveram concentração de suco igual a 12,49\%. Para o maracujazeiro-amarelo, Fontes (2005) e Carvalho et al. (2000) não observaram diferenças na concentração de suco em relação ao aumento na adubação nitrogenada, e Carvalho et al. (1999) verificaram que o incremento da adubação potássica aumentou a concentração de suco.

Melleti et al. (2005) encontraram espessura de casca de frutos do maracujazeiro doce que variaram de 7,1 a 11,3 mm. Detoni et al. (2001), trabalhando com maracujazeiro doce em condições de campo, obtiveram espessura da casca com média de 11,2 mm. O valor encontrado no presente trabalho para espessura de casca, no tratamento completo, foi de $9,30 \mathrm{~mm}$.

Observa-se na Tabela 3 que plantas de maracujazeiro doce cultivadas sob deficiências de N, P e K produziram frutos com teores de sólidos solúveis totais (SST) menores do que aqueles obtidos em plantas cultivadas sob o tratamento completo.

Vasconcellos et al. (1993) obtiveram, em frutos do maracujazeiro doce cultivado em Botucatu-SP, teor de sólidos solúveis totais igual a $18,45^{\circ} \mathrm{Brix}$. Veras et al. (2000) obtiveram, nas condições de Brasília-DF, teores de sólidos solúveis totais nos valores de $19,7^{\circ}$ Brix para frutos coletados no período de outubro a dezembro e $18,7^{\circ}$ Brix quando coletados no período de abril a julho. Detoni et al. (2001), em condições de Pato Bragato -PR, obtiveram teor médio de SST de $18,4^{\circ}$ Brix. No presente trabalho, os valores de SST, para o tratamento completo, foi de $20,8^{\circ}$ Brix, sendo maiores que os encontrados pelos referidos autores. Carvalho et al. (2000) verificaram que a adubação nitrogenada não influenciou nos teores de sólidos solúveis totais em maracujá-amarelo.

Carvalho et al. (1999) observaram que o incremento na adubação potássica promoveu aumento linear na concentração de sólidos solúveis no suco do maracujazeiro-amarelo; resultados semelhantes foram encontrados em melancia por Cecílio Filho e Grangeiro (2004). Uma das funções do K é seu importante papel no transporte da sacarose (Marschner, 1995).

Observa-se na Tabela 3 que a acidez total titulável (ATT) foi menor no tratamento com deficiência de K. O valor de ATT, 1,70\%, no suco do tratamento completo encontra-se acima daquele encontrado por Veras et al. (2000), quando os frutos foram coletados de outubro a dezembro $(1,41 \%)$ e abaixo quando coletados no período de abril a julho (2,05\%). Damatto Júnior et al. (2005) encontraram médias de ATT de 2,21\% no suco de maracujazeiro doce.. Marschner (1995) relata que mudanças na atividade das enzimas e nos compostos orgânicos que ocorrem durante a deficiência de $\mathrm{K}$, afetam a composição nutricional e a qualidade dos produtos colhidos; em muitos casos, as desordens têm relação direta com o teor de ácido cítrico.

A acidez, causada pelos ácidos orgânicos, é uma característica importante no que se refere ao sabor de muitas frutas. A baixa acidez dos frutos do maracujazeiro doce atrai muitos consumidores. No tratamento com deficiência de $\mathrm{P}$, os valores de $\mathrm{pH}$ do suco foram mais baixos, ou seja, mais ácido, em relação ao tratamento completo (Tabela 3). O valor de $\mathrm{pH} 3,53$ no suco do tratamento completo encontra-se dentro da faixa de valores de $\mathrm{pH}$ 3,0 e 3,6, relatados por Manica e Oliveira (2005). Detoni et al. (2001), em condições de Pato Bragato-PR, verificaram valores médios de $\mathrm{pH}$ iguais a 3,82 .

Verifica-se na Tabela 3 que as deficiências de $\mathrm{N}, \mathrm{K}$ e $\mathrm{S}$ reduziram os teores de vitamina $\mathrm{C}$ dos frutos do maracujazeiro doce enquanto a deficiência de $\mathrm{P}$ incrementou. A redução foi de $29,5 \%$ para N, 19,2\% para K e 19,8\% para S, e o incremento foi de $53 \%$ para $\mathrm{P}$ em relação ao tratamento completo.

Dentro dos fatores que influenciam no teor de vitamina $\mathrm{C} \mathrm{em}$ frutos e vegetais, Lee e Kader (2000) relatam que altas taxas de fertilizantes nitrogenados tendem a decrescer os teores de vitamina $\mathrm{C}$ e ainda que, em geral, os teores de vitamina $\mathrm{C}$ correlacionam com os teores de enxofre. Para os autores citados, vegetais que contêm altos teores de vitamina $\mathrm{C}$ também têm alto teor de compostos com enxofre. Trabalhando com fontes e doses de $\mathrm{N}$ em mamoeiro, Marinho et al. (2001) verificaram que a aplicação de nitrato de amônio promoveu maior produção de frutos com teor mais elevado de vitamina $\mathrm{C}$.

Para o K, Carvalho et al. (1999) observaram que o incremento na adubação potássica não afetou a concentração de vitamina $\mathrm{C}$ no suco do maracujazeiro-amarelo. Spironello et al. (2004), estudando os efeitos da adubação com NPK na produção e qualidade dos frutos de abacaxizeiro, verificaram que o incremento das doses de $\mathrm{K}$ aumentou os teores de vitamina $\mathrm{C}$ no suco do abacaxi. Segundo Smirnoff et al. (2001), o suprimento de B afeta a síntese de ácido ascórbico; plantas deficientes em $\mathrm{B}$ podem ter baixos teores de ácido ascórbico. Para maracujazeiro doce, não foi verificado influência do $\mathrm{B}$ no teor de vitamina $\mathrm{C}$.

$\mathrm{Na}$ Tabela 4, são apresentados os teores dos macronutrientes e de B, na matéria seca foliar do maracujazeiro doce, aos 240 dias após o início da aplicação dos tratamentos, período de avaliação dos frutos. Verifica-se que os teores de nutrientes, nos respectivos tratamentos, foram sempre menores que aqueles obtidos no tratamento completo.

\section{CONCLUSÕES}

1) Todas as deficiências estudadas reduziram o número de frutos por planta, com maior intensidade no tratamento deficiente em $\mathrm{Mg}$, que não floresceu.

2) A deficiência de $\mathrm{N}$ incrementou a porcentagem de casca e a espessura dos frutos e reduziu a porcentagem de semente no fruto, $\mathrm{o}{ }^{\circ}$ Brix e o teor de vitamina $\mathrm{C}$ no suco.

3) A deficiência de $\mathrm{P}$ aumentou a espessura e a porcentagem de casca dos frutos e o teor de vitamina $\mathrm{C}$ no suco e reduziu o ${ }^{\circ} \mathrm{Brix}$ e o $\mathrm{pH}$ do suco.

4) A deficiência de $\mathrm{K}$ reduziu o ${ }^{\circ}$ Brix, a ATT e o teor de vitamina C no suco.

5) A deficiência de $\mathrm{S}$ reduziu o teor de vitamina $\mathrm{C}$ no suco.

6) As deficiências de Ca e B não exerceram influência nas características químicas e físicas dos frutos e do suco do maracujazeiro doce.

\section{REFERÊNCIAS}

ARAÚJO, R. DA C.; BRUCKNER, C.H.; MARTINEZ, H.P.; SALOMÃO, L.C.C.; VENEGAS, V.H.A.; DIAS, J.M.M.; PEREIRA, W.E.; SOUZA, J.A. Crescimento e produção do maracujazeiroamarelo em resposta à nutrição potássica. Revista Brasileira de Fruticultura, Jaboticabal, v.27, n.1, p.128-131, 2005.

BOLOGNA, I.R. Adubação boratada em pomar de laranja-pêra-rio afetada pela clorose variegata dos citros, 2003. 78f. Tese (Doutorado em Agronomia) - Escola Superior de Agronomia "Luiz de Queiroz" Universidade de São Paulo, Piracicaba, 2003. 
CARVALHO, A.J.C. de; MARTINS, D.P.; MONNERAT, P.H; BERNARDO, S. Adubação nitrogenada e irrigação no maracujazeiro-amarelo. I Produtividade e qualidade dos frutos. Pesquisa Agropecuária Brasileira, Brasília, v.35, n.6, p.1.101$1.108,2000$.

CARVALHO, A.J.C. DE; MONNERAT, P.H.; MARTINS, D.P.; BERNARDO, S. Produtividade e qualidade do maracujazeiroamarelo em resposta à adubação potássica sob lâminas de irrigação. Revista Brasileira de Fruticultura, Jaboticabal, v.21, n.3, p.333-337, 1999.

CECÍLIO FILHO, A.B.; GRANGEIRO, L.C. Qualidade de frutos de melancia sem sementes em função de fontes e doses de potássio. Ciência e Agrotecnologia, Lavras, v.28, n.3, p.570-576, 2004.

DAMATTO JR, E.R.; LEONEL, S.; PEDROSO, C.J. Adubação orgânica na produção e qualidade de frutos de maracujá-doce. Revista Brasileira de Fruticultura, Jaboticabal, v.27, n.1, p.188190, 2005.

DETONI, A. M.; TESSER, SAIONARA, M.; LUCHTENBERG, W.; FERREIRA, G. Desenvolvimento inicial de maracujazeiro doce (Passiflora alata Dryander) no município de Pato Bragado-PR. In: ENCONTRO ANUAL DE INICIAÇÃO CIENTÍFICA, 10., 2001. Ponta Grossa: UEPG, 2001. v.3, p.21-22.

FONTES, P.S.F. Eficiência da fertirrigação com nitrogênio e avaliação do estado nutricional do maracujazeiro-amarelo utilizando o DRIS. 2005. 100f. Tese (Doutorado em Produção Vegetal) - Universidade Estadual do Norte Fluminense Darcy Ribeiro, Campos dos Goytacazes, 2005.

HUNSCHE, M.; BRACKMANN, A.; ERNANI, P.R. Efeito da adubação potássica na qualidade pós-colheita de maças "Fuji". Pesquisa Agropecuária Brasileira, Brasília, v.38, n.4, p.489496. 2003.

JOHNSON, C.M.; STOUT, P.R.; BROYER, T.C.; CARLTON, A.B. Comparative chorine requirements of different plant species. Plant and Soil, Dordrecht, v.8, p.337-357. 1957.

LEE, S.K.; KADER, A.A. Preharvest and postharvest factors influencing vitamin $\mathrm{C}$ content of horticultural crops. Postharvest Biology and Technology, Amsterdan, v.20, p.207-220, 2000.

MALAVOLTA, E.; VITTI, G.C.; OLIVEIRA, S.A. DE. Avaliação do estado nutricional das plantas: princípios e aplicações. Piracicaba: POTAFOS, 1997. 319p.
MANICA, I.; OLIVEIRA Jr., M.E. DE. Maracujá no Brasil. In: Manica, I. Brancher, A., Sanzonowics, C., Icuma, I.M., Aguiar, J.L.P. de, Azevedo, J.A. de, Vasconcellos, M.A. da S., Junqueira, N.T.V. Maracujá-doce: tecnologia de produção, pós-colheita, mercado. Porto Alegre: Cinco Continentes, 2005. p.11-26.

MARINHO, C.S.; OLIVEIRA, M.A.B. DE; MONNERAT, P.H.; VIANNI, R.; MALDONADO, J.F. Fontes e doses de nitrogênio e a qualidade dos frutos do mamoeiro. Scientia Agrícola, Piracicaba, v.58, n.2, p.345-348, 2001.

MARSCHNER, H. Mineral nutrition of higher plants. $2^{\text {nd }}$ ed. London: Academic Press, 1995. 889p.

MELETTI, L.M.M.; BERNACCI, L.C.; SOARES-SCOTT, M.D.; AZEVEDO FILHO, J.A.; MARTINS, L.C. Variabilidade genética em caracteres morfológicos, agronômicos e citogenéticos de populações de maracujazeiro-doce (Passiflora alata Curtis). Revista Brasileira de Fruticultura, Jaboticabal, v.25, n.2, p.275278,2003

SMIRNOFF, N.; CONKLIN, P.L.; LOEWUS, F.A. Biosynthesis of ascorbic acid in plants: a renaissance. Annual Review of Plant Physiology and Plant Molecular Biology, Palo Alto, v.52, p.3767. 2001.

SPIRONELLO, A.; QUAGGIO, J.A.; TEIXEIRA, L.A.J.; FURLANI, P.R.; SIGRIST, J. M. M. Pineapple yield and fruit quality effected by NPK fertilization in a tropical soil. Revista Brasileira de Fruticultura, Jaboticabal, v.26, n.1, p.155-159. 2004.

SILVA, H.A. DA; CORRÊA, L. DE S.; BOLIANI, A.C. Efeitos do sistema de condução, poda e irrigação na produção do maracujazeiro doce. Revista Brasileira de Fruticultura, Jaboticabal, v.26, n.3, p.450-453, 2004.

VASCONCELLOS, M.A. DA S., CEREDA, E., ANDRADE, J.M. DE B., BRANDÃO FILHO, J.U.T. Desenvolvimento de frutos de maracujazeiro doce (Passiflora alata Dryand), nas condições de Botucatu-SP. Revista Brasileira de Fruticultura, Jaboticabal, v.15, n.1, p.153-158, 1993.

VERAS, M.C.M.; PINTO, A.C. DE Q.; MENESES, J.B. DE. Influência da época de produção e dos estádios de maturação nos maracujás doce e ácido nas condições de cerrado. Pesquisa Agropecuária Brasileira, Brasília, v.35, n.5, p.959-966, 2000. 